\title{
Long term planning for a block cave project. Is the value being missed?
}

\author{
W Bennett Mining Plus, Australia
}

\begin{abstract}
Block caving is a highly efficient mining method whereby deposits are mined from underground at low costs, approaching those of an open pit. As more projects successfully use this method, and confidence and expertise grow, it is likely that more projects will be mined in this way. Over the last few years, the author has been involved in a number of caving projects from early-stage studies, to feasibility, construction and production. This paper describes some of the mine planning challenges encountered in these projects. It also looks into the Mining Plus crystal ball to see what the future of block caving might look like. Based on a dissection of these projects, this paper makes three assertions. Firstly, strategic planning for a block cave shares more with the open pit than with other underground methods. Secondly, optimising a block cave can in fact be more complex than optimising an open pit. And finally, that as future technologies unlock opportunities to increase project value, the mine planning challenges will become even more complex. In conclusion, the question is posed: With all of the complexity and challenges of planning a block cave, is value being missed?
\end{abstract}

\section{Introduction}

\subsection{Background}

It is the author's opinion that block caving is growing in applicability as a result of three complementary forces. Firstly, demand for minerals that suit block caving methods, such as copper, is likely to increase following the trend for electrification. Secondly, big open pit projects are likely to become scarcer, with the best of the biggest already discovered and on the way to being mined out. Finally, as industry experience of block caves grows, the method will improve, both in the performance of caving operations and in the understanding of the risks and uncertainties involved in these projects.

\subsection{Characteristics of block caves, open pits and other underground methods}

Although block caving is an underground method, from a strategic planning point of view it has many characteristics more commonly associated with open pit mining.

- The cost of block caving is very low. Although not as low as open pit mining it is significantly cheaper than other underground methods

- The production rates are much higher than other underground methods can typically achieve

- The mining shapes of both block caves and open pits are constrained by geotechnical rules which do not necessarily follow the geometry of the mineralisation

For block caves, as with some open pit projects, a low cost leads to large mining inventories, where even very low grades can be mined economically. This, in spite of the high production rates leads to long project lives where the effect of time discounting on project economics is significant. This similarity makes an open pit approach to strategic mine planning, where mining shapes are designed to create high margin shells that can be mined first before mining lower margin shapes later, very appropriate for block caves. 
With regard to the mining shape, there are a range of different underground mining methods (excluding block caving) which can efficiently extract and closely follow the geometry of the mineralisation over a range of geometries. Often there is some planned dilution/loss of recovery, where the angle, width or pillar thickness does not quite match the orebody, but this is minimal. To quote Peter Lock (personal communication with Peter Lock, Rosebery Mine, Stope Note Review Meeting 2007) when reviewing one of the author's stope designs, "If you are taking that much waste and leaving that much of the ore in the ground, then you are probably using the wrong mining method".

In a block cave, this is not the case and the planned dilution can be significant. Due to strong geotechnical constraints governing the shape of a viable cave and a very low mining cost, optimum shapes can often contain a large quantity of planned dilution. A similar situation is found in the open pit where very low mining costs (per tonne) allow large volumes of waste to be mined to make a geotechnically stable (slope angle) mining shape (albeit that in the pit although this waste must be mined it does not have to be processed). This comparison is shown in Figure 1.

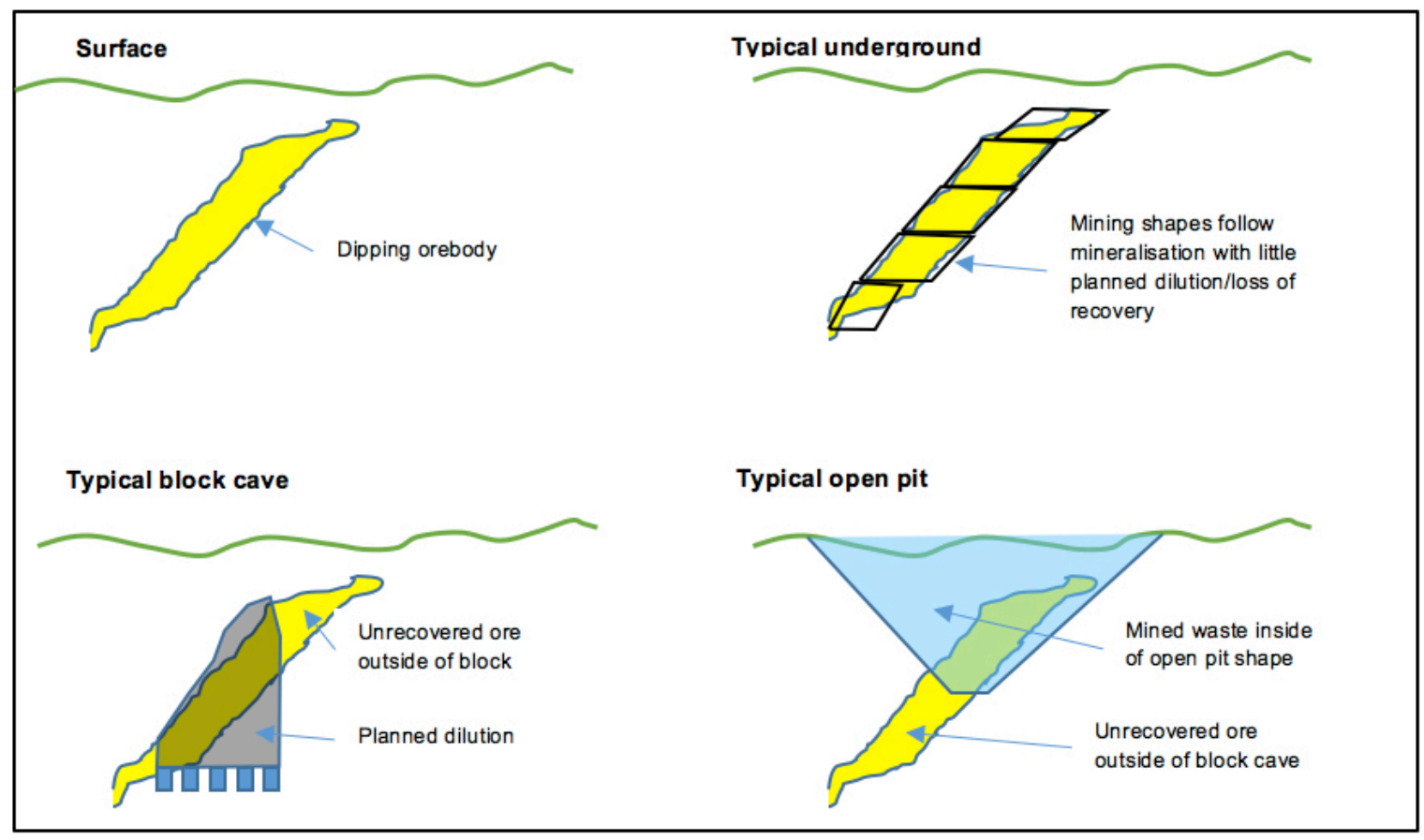

Figure 1 Typical mining geometries for stoping, block caving and open pit mining method

\subsection{Block cave strategic planning challenges}

Despite greater similarities with an open pit than underground, optimising a block cave is a more complex process than optimising an open pit to the same degree. The design of open pits can be optimised rigorously, with a mature set of mine planning rules and algorithms. Algorithms and processes for optimising block caves exist, but the problem is more complex than the open pit optimisation. This is due in part to the following factors:

- Open pits have to start from the surface, whereas cave footprints can start from any location where there is ore above.

- Block cave mining shapes have to perform multiple functions within the mining cycle, first allowing cave propagation to break the ore, then enabling the ore to flow to the extraction level, whilst maintaining geotechnical stability of the work areas. In an open pit, the slope angle maintains geotechnical stability, but is not required to break the ore or facilitate ore flow. This makes the mining shape parameters for block caves more complex and more difficult to define. 
- When a deposit is large enough to contain multiple footprints these footprints are typically inter-related, with the optimisation of one affecting the optimisation of the others.

- Evaluation of the tonnes and grade of an open pit is a simple insitu evaluation. Evaluation of a block cave must consider the effects of flow (which leads to mixing).

- Materials handling in a pit (haul ramp) increases as the pit grows. In a block cave, it has to be put in at the beginning and is subject to variable geotechnical criteria (footprint stability, crusher stable location).

\section{Mining Shapes}

One key part of the planning process is the definition of the geometry of a viable mining shape. For an open pit, typical shape parameters used for the optimisation process are:

- Slope angle

- Minimum bench/pushback width

These shape parameters, coupled with a geological block model and some economic and mining assumptions are enough to generate a mathematically optimum pit shell. Some typical open pit shape constraints are shown schematically in Figure 2.

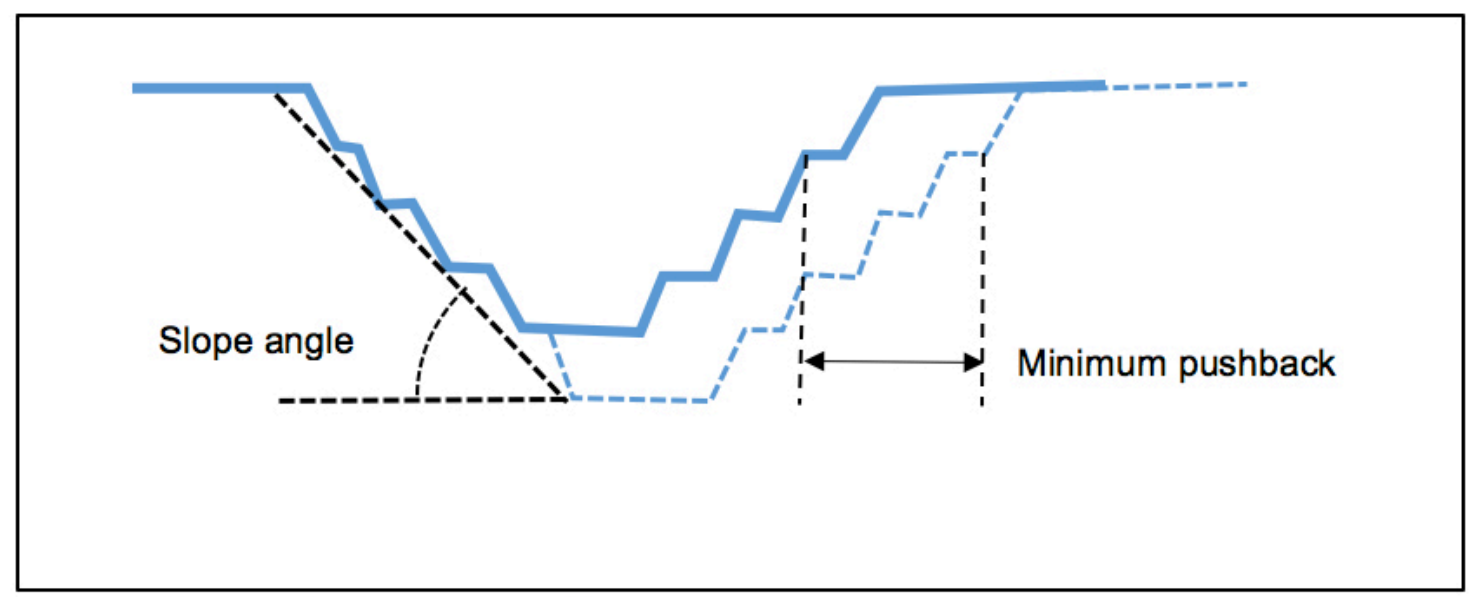

Figure 2 Typical open pit shape constraints

Viable block cave shapes can also be defined by a series of parameters. However, when compared with the shape parameters for an open pit, the list is longer, and unfortunately the rules less well defined. For a block cave, shape parameters might govern:

- Minimum footprint hydraulic radius

- Maximum height of draw (HOD)

- Minimum height of draw

- Angle of break

- Minimum expansion width for subsequent caves

- Local variation in height of draw

- Footprint and footprint pillar minimum spans 
These rules are shown graphically in Figure 3 and Figure 4. Although there are empirical methods for determining some of these shape parameters so that an initial design can be completed, others must be found by geotechnical modelling of a design. This sets up a design, simulate, refine iterative loop, making optimisation of the initial mining shapes a more involved process.

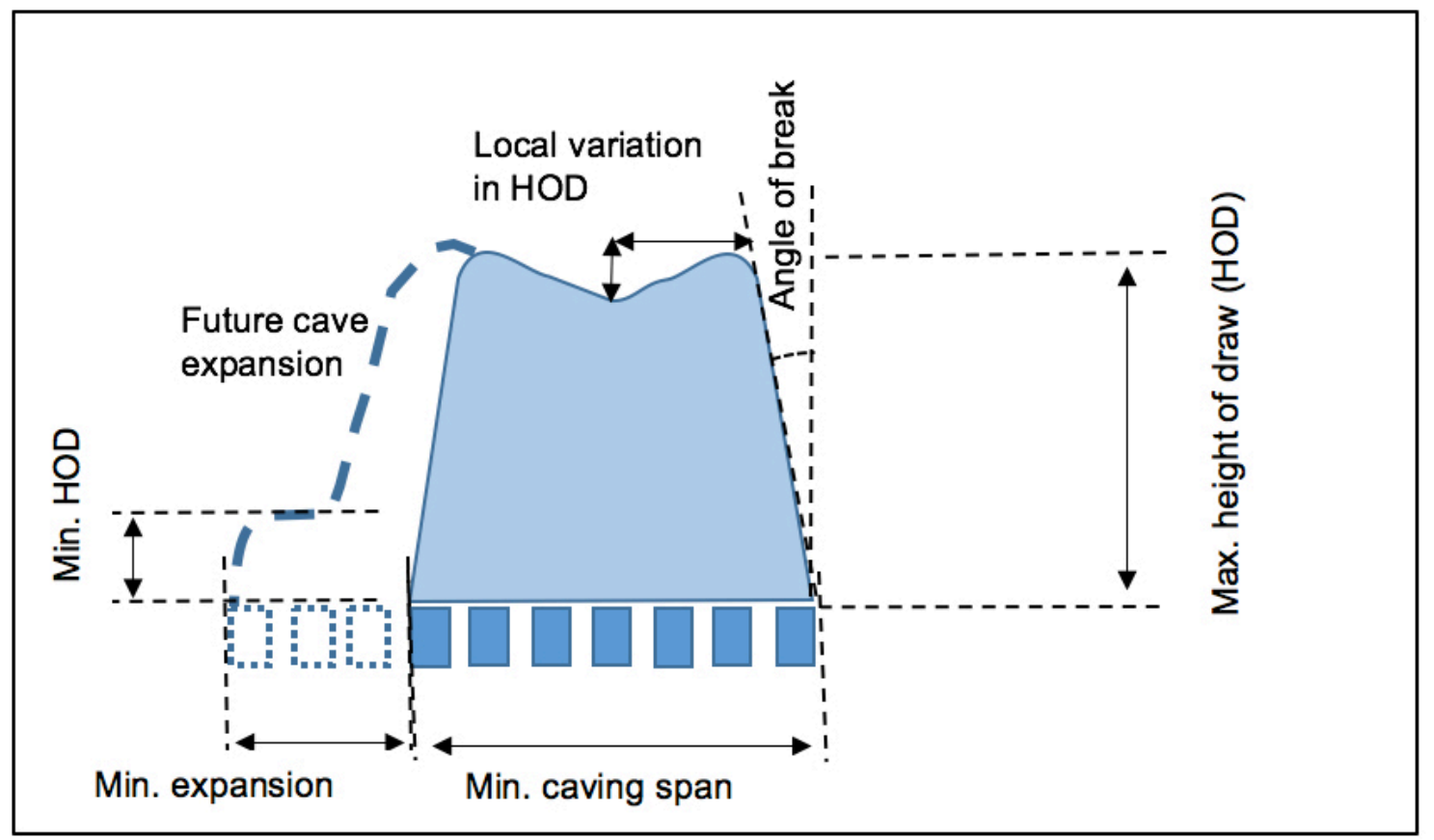

Figure 3 Typical block cave shape constraints (section view)

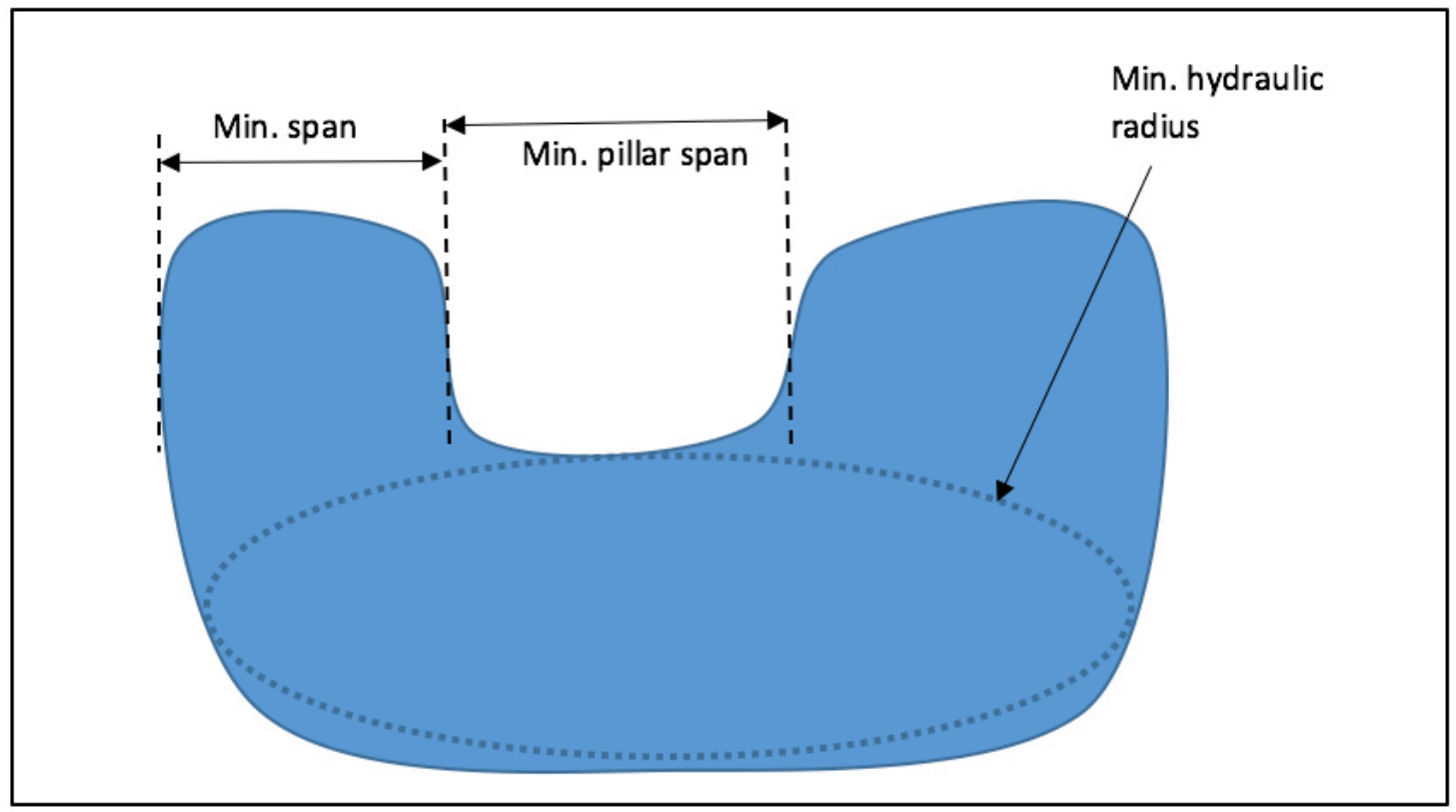

Figure 4 Typical block cave shape constraints (plan view)

\subsection{Summary}

In summary, although it is an underground method, from a strategic planning point of view, block caves share many of their characteristics with open pits, and consequently benefit from being planned and optimised with a similar process. However, the optimisation of a block cave design is a more difficult problem than the pit due to the difficulty in defining the constraints, the interdependence of the optimisation steps and the greater degrees of freedom. Examples of some of these challenges will be described in the following case studies. 


\section{$2 \quad$ Case studies}

The following case studies describe some of the types of problems encountered in strategic planning for block caving projects that the author has worked on. For each case, the likely result of following the open pit optimisation process is described (for the hypothetical case where the same deposit style was near surface) and compared with the process of optimising a block cave.

\subsection{Sub-horizontal stacked lenses}

In this case, the geological model consisted of multiple sub-horizontal stacked lenses. When bulked together the average grade of material was suitable for block caving. However, the case presented a number of design challenges:

The stacked lenses exhibited geological continuity, but independent variations in:

- Grade

- Lens thickness

- Lens spacing

- Distance to potential footprint (and hence degree of planned dilution)

This led to an erratic variation in both best height of draw over the horizontal extents of the footprint and the shape of the footprint itself.

The stacked lenses had a large horizontal extent (greater than the minimum required for caving), which allowed for multiple footprints, with each one at potentially a different RL. This presented the challenge of how to choose the best separation position for the different footprints in order to optimise each one.

These impractical local variations in the optimised shapes (Figure 5) needed to be conditioned out, with a degree of subjectivity involved in what was and was not a practical stable footprint and shape. Likewise, the decision of where to split the footprint to individually optimise the floor elevations involved a combination of analysis and subjectivity.

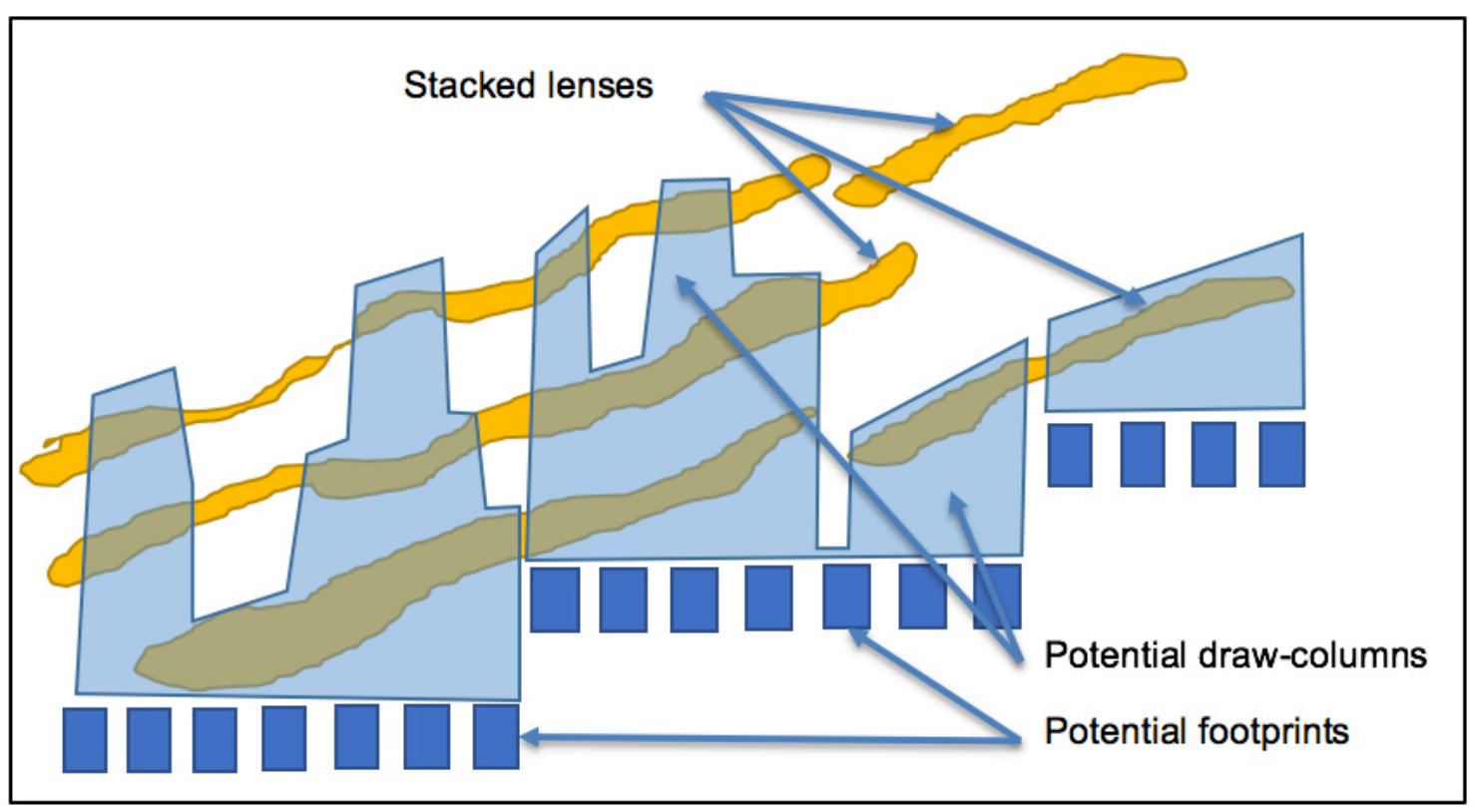

Figure 5 Schematic section view of block cave optimisation of stacked lenses problem, showing erratic and impractical variations in best height of draw 
If the same type of deposit (albeit at a shallower depth) was optimised for an open pit, these challenges would have been resolved by the optimisation, with little ambiguity over what is a practical shape, with the result being a true optimisation (of the input parameters). Conversely in a stoping or entry method the design would have closely followed the mineralisation.

\subsection{Poddy orebody}

Unlike the previous case, which displayed strong geological continuity that did not match the caving geometry, this deposit was made up of multiple high grade "pods", surrounded by lower grade material. Individual pods were smaller than the minimum caving size, so each potential cave shape grouped together different pods. The challenges involved were:

- As with the previous case, the optimised cave shapes could easily be very ugly (Figure 6) and required conditioning with a degree of subjectivity around what was and was not a practical shape.

- Various methods were used to determine which areas to group together into potential cave footprints for optimisation. However, it was not certain that a better grouping of different "pods" did not exist.

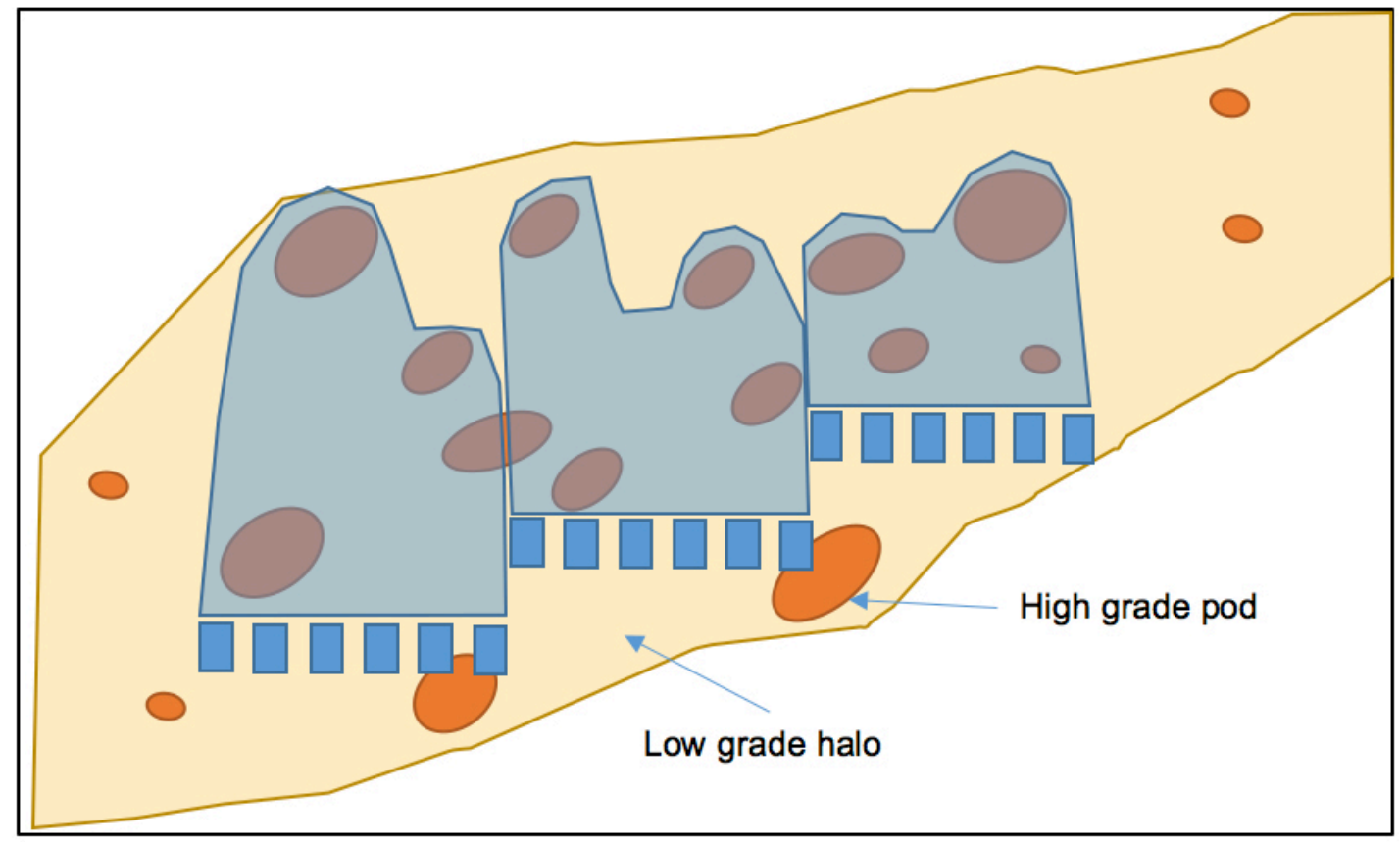

Figure 6 Schematic section view of block cave optimisation of poddy mineralisation

As with the previous case, if the mineralisation had been suitably shallow to be mined as an open pit, then open pit optimisation of the same deposit style would result in a more readily implementable shape that would require less conditioning, while its mathematical optimality would be guaranteed.

\subsection{Ground conditions constrained}

As described previously in this paper, geotechnical considerations are very strong drivers of block cave design. Essentially, for a block cave to succeed, the ground conditions must be both poor enough to allow caving, while competent enough to allow stable excavations to recover the broken ore.

In this case, ground conditions were the main design driver, with a zone of mineralised but very poor rockmass above a zone of much lower grade, but more competent rock (Figure 7). Geotechnical design guidelines stated that the footprint had to be located in the competent rock, but complicating things further was a series of faults. Although they were not "no-go-zones", these faults needed to be crossed at certain angles and stand-offs. 


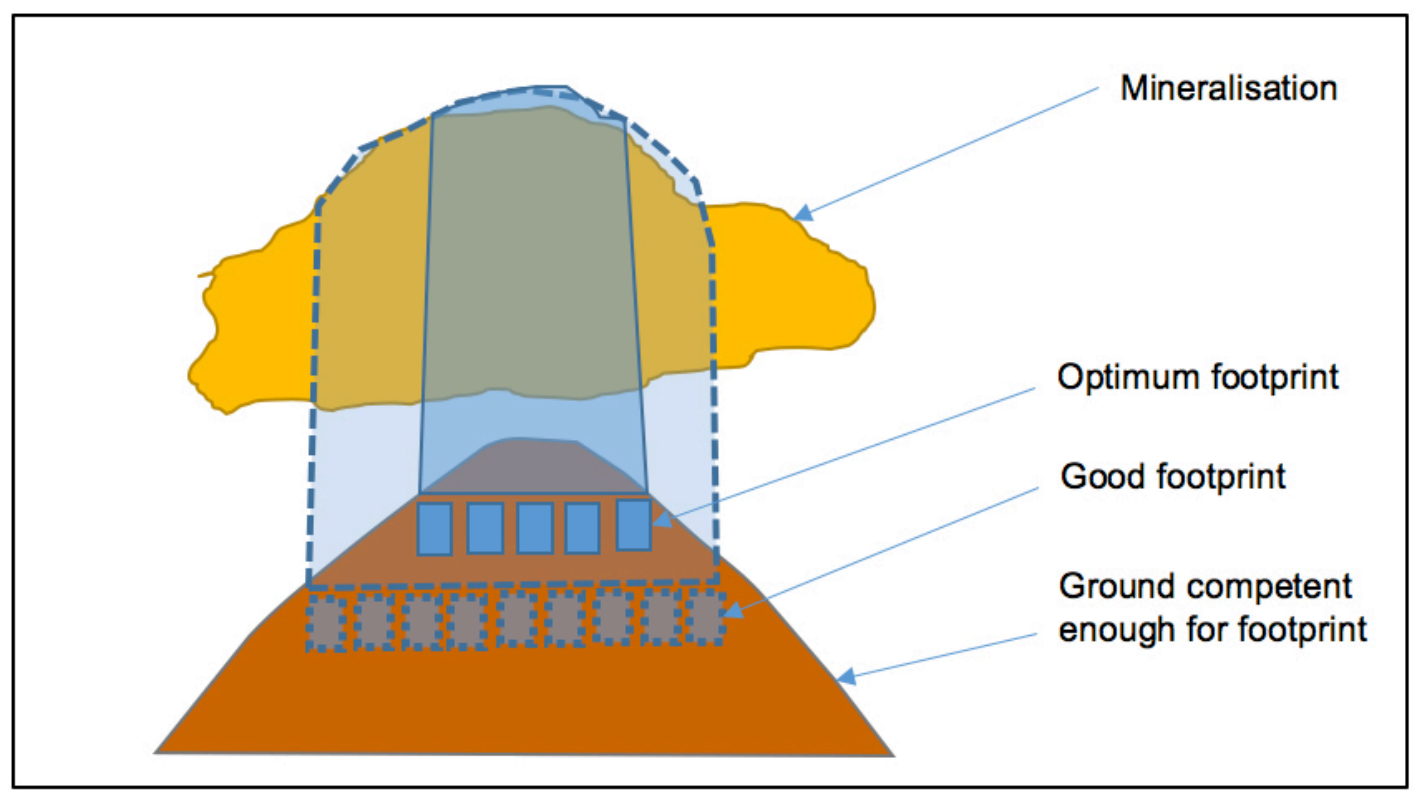

Figure 7 Schematic section view of design options for a ground conditions constrained block cave project

The initial optimisation resulted in a footprint which was too severely compromised by these faults to be considered practical. Unlike the previous case studies, the caving shapes generated by optimisation required little manual conditioning, so it was possible to rapidly generate a range of different footprint optimisations at various footprint elevations and cut-off grades. From these, the optimisations whose value was within $5 \%$ of the impractical optimum were selected (Figure 7). These sub-optimal but good options were then reviewed with the geotechnical engineers to select a footprint which was both viable and returned a high discounted value.

\section{$2.4 \quad$ Subsidence constrained}

An exclusion zone on the surface is a typical constraint of an open pit optimisation problem. Examples of such zones include a sea-wall, river or an area of significance to the local community. In this case study an exclusion zone covered the subsidence on surface created by a potential block cave. In open pit optimisation, the exclusion zone can be incorporated into the optimisation by making the mining cost of blocks in the exclusion zone very high. A similar approach was used in this case, with blocks within a defined angle of the exclusion zone removed from the footprint finder. The study was conceptual, with clear geotechnical guidance of the exclusion zone angle. However, it is considered likely that after geotechnical modelling of the design a more complex criteria can be applied where the subsidence zone is a function of tonnes drawn and the proximity to the exclusion zone. Optimisation under these considerations will be significantly more complex than an open pit under the same constraints.

\subsection{Vertical multi-lift with grade variation}

For block caves, low production costs lead to large volumes of material that can be considered ore and consequently long mine life (potentially multi-decade) where the effect of the time value of money is a key driver of block cave design. In single or independent footprint block caves the cave can be optimised on its discounted value relatively simply by including the effects of discounting in the best height of draw calculation. However, in multi-lift situations the optimisation process is more complex.

In this case the deposit was very steeply dipping (near vertical) with the grade varying vertically. As shown in Figure 8, the optimum design under a discounted cash flow basis targets the higher grade and actually leaves a portion of material unrecovered (although it seems likely that a higher maximum height of draw would be possible) between the two lifts. 


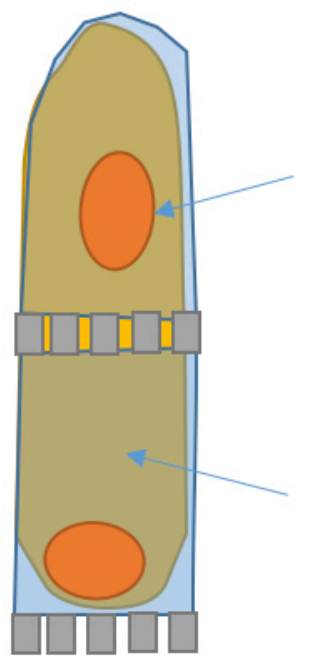

Optimum recovery

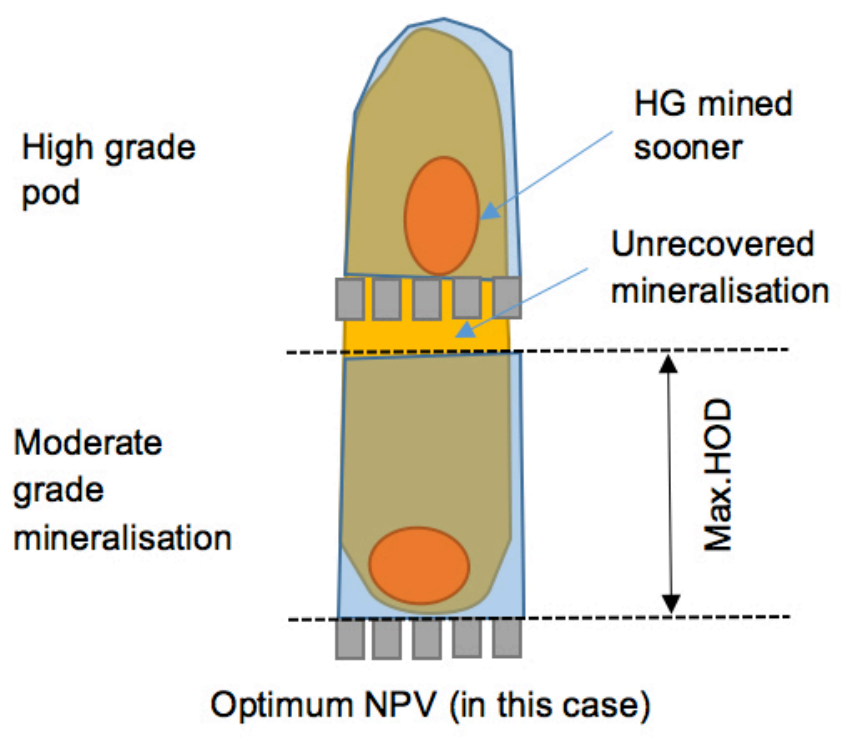

Figure 8 Schematic section view of multi-lift block cave with options to optimise recovery or NPV

As the number of lifts increase, the number of combinations of the different lift positions that need to be optimised to evaluate increases with a power (exponential) relationship. When compared with an open pit optimisation problem, the huge number of combinations to test is a function of the greater degree of freedom in the block cave design. The pit must start mining at the surface and progress down (and outwards) while there is no such constraint with starting position (footprint elevation) in a block cave.

\subsection{Sub-vertical multi-lift with grade variation}

This case follows the same principle as the previous case, with the locations of multi-lift footprints chosen based on the discounted cash flow and consequently strongly driven by the vertical grade distribution. In this case, the situation was complicated by the sub-vertical dip of the deposit (Figure 9), which makes planned dilution and recovery a driver of footprint $\mathrm{RL}$, as well as the location of higher grade.
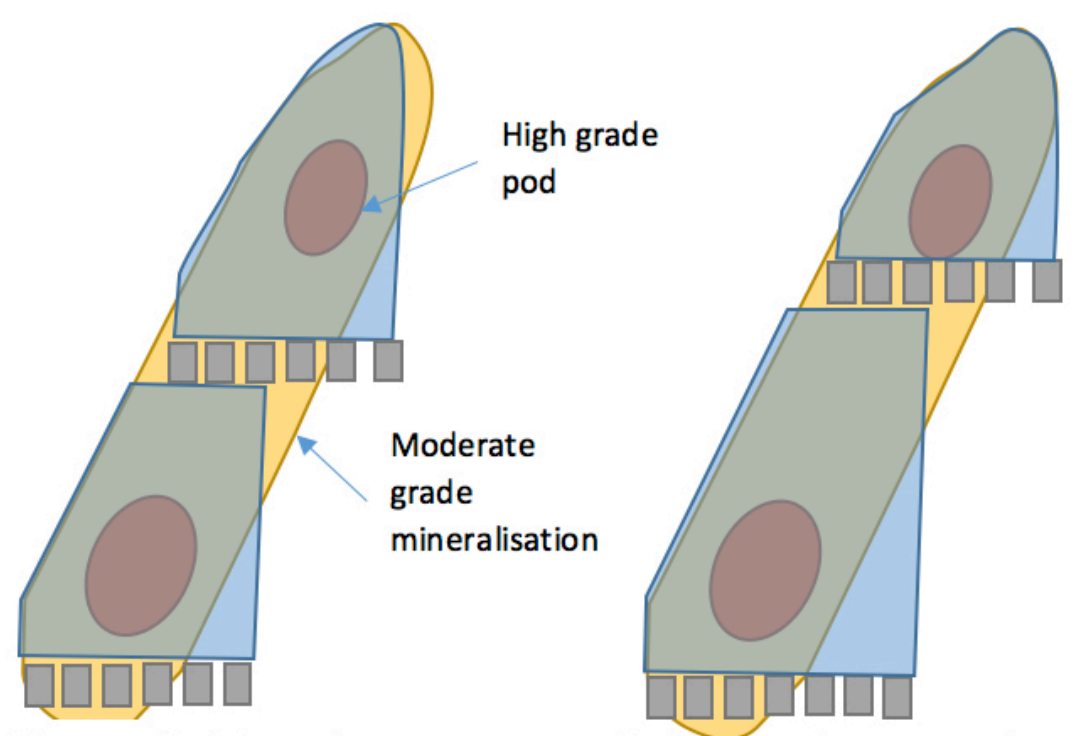

Expedited high grade. Greater planned dilution

Figure 9 Schematic section view of optimisation options for a multi-lift sub-vertical deposit 


\subsection{Subdividing a potential footprint}

In this case, initial footprint finding resulted in a footprint considerably larger than was required to meet the minimum span for caving or the production rate. A footprint run at a lower revenue factor (higher cut-off) was possible, but was located in the centre of the full footprint, preventing the remaining material from being mined due to the minimum expansion span criteria. Finding the optimal footprint then required a number of scenarios to be tested (Figure 10) all of which conformed to the cave shape constraints, but whose value had to be compromised to do so:

- Single large footprint with low draw rates and high discounted cost of footprint establishment

- Small high-grade footprint to more closely match production rate but much lower recovery of ore

- Small high-grade footprint followed by diluted footprint expansions to meet minimum span criteria

- Various combinations of split footprint that maintained two minable cave geometries without increasing the footprint size

In this case, the optimum was the last option, where the footprint was split into two minable portions. However, the best location for the split was found by brute force, testing a number of orientations, rather than any more elegant procedure.

When compared with the open pit, this problem is similar to that of choosing the best combinations of pit shells to make up push-backs with viable widths.

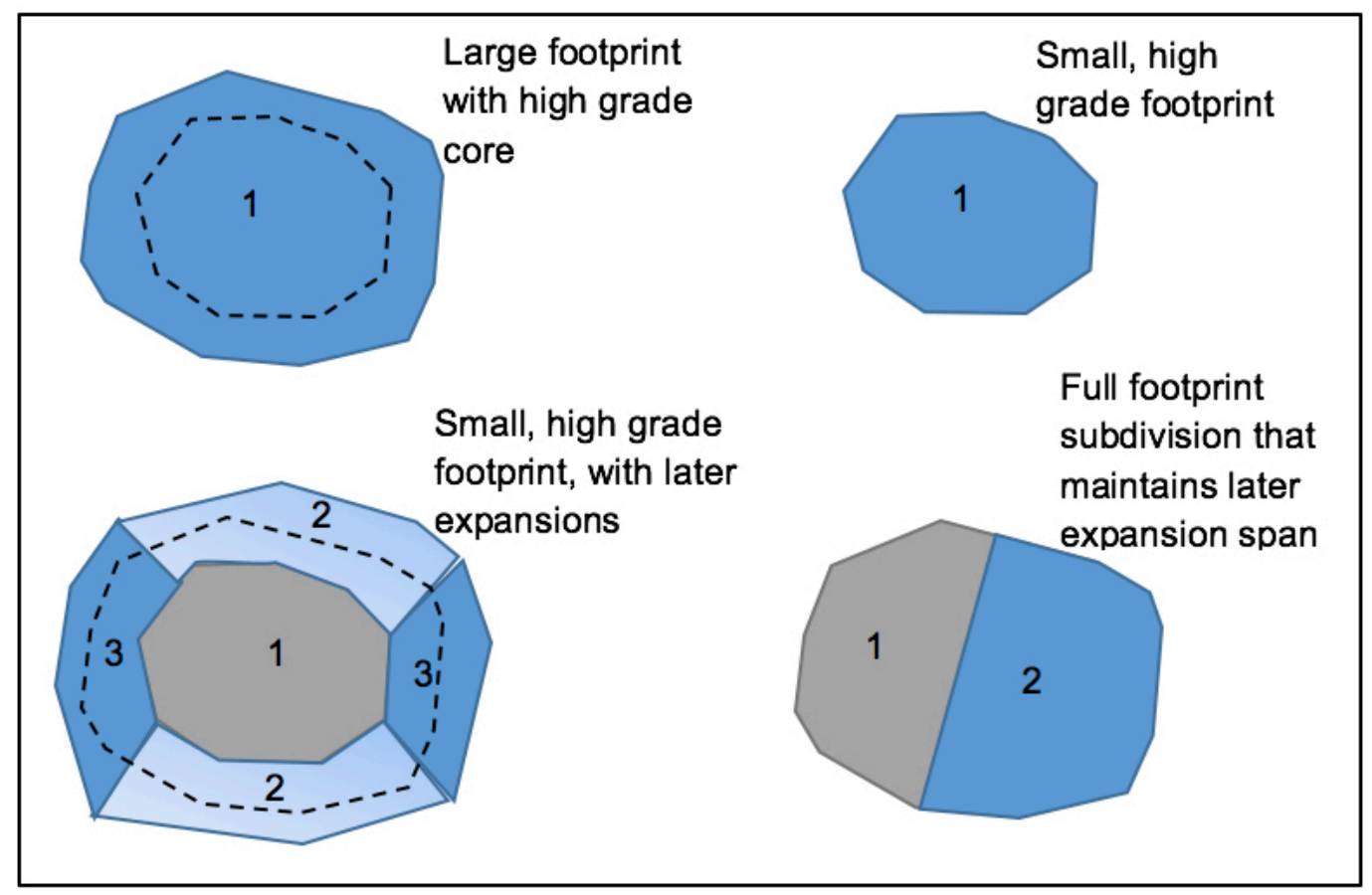

Figure 10 Schematic plan view of options for sub-dividing a footprint

\subsection{Very large mineralised zone with multiple footprints in vertical and horizontal directions}

In this final case, the mineralised zone was large enough to be divided into multiple footprints in all three directions. A process of iteration was used to identify high grade caves which did not compromise the shapes of the lower grade caves around them, optimise those footprints (elevation and height of draw) according to their timing in a high-level schedule and then adjust the boundaries between the caves and repeat. 
The design produced by this iterative process was good but unlikely to be optimum. The case demonstrates the degree of flexibility available in a block caving project, which is not present in an open pit, where all mining is constrained to start at the top, thus removing a variable and simplifying the optimisation process.

\section{Implications of future technologies}

Many of the caving projects the author has been involved with have multi-decade life of mine plans, so it is often appropriate to consider the impact of potential future technologies. Although some of these technologies have the potential to improve the economics of caving projects, the objective here is not to predict the future of block caving, but to understand the impact of potential technologies on the mine planning and design process. Some of these technologies can be assessed using the existing mine planning optimisation methods, with the impact of the technology included in a change of parameters (mining cost for example). Others will require a modified optimisation method to fully capture the value that they will add. A short, non-exhaustive list of technologies has been considered.

\subsection{Explosive technology}

New drill and blast technology (electronic and wireless detonators) greatly enhance what is possible using drill and blast mining techniques. One application is undercut-less block caves (Newcrest Mining Limited 2018), where the cave is undercut from the drawbell, without a dedicated undercut sublevel.

Although undercut-less caving has the potential to reduce cave establishment costs and significantly improve the economics of low height of draw caves (where the cave establishment cost is a higher proportion of the overall) the technology does not affect the optimisation process. The benefits of the technology can be captured in the footprint establishment cost parameter with the cave design then optimised using existing techniques.

\subsection{TBM and rapid tunnelling methods}

Tunnel boring machines (TBM) can achieve development rates far higher than conventional drill and blast. Block caves must start mining from the bottom of the cave, which must be accessed first through a decline or shaft. Mining these accesses faster will expedite the start of production.

In some projects this type of rapid development can clearly improve project NPV at the cost of the increased capital of the TBM. However, conventional trade-off studies can be used to assess their value, without the need for any significant changes to the cave optimisation process.

\subsection{Ore-sorting and stockpiling}

Ore-sorting describes the process of separating mined material into different ore types. This may be done:

- After mining using mechanical separation

- By segregating ore types underground through campaign drawing or segregated materials handling streams

Stockpiling (where some mined ore is stored before processing later) allows the best material to be processed at the right time in situations where the mining rate is higher than the processing rate. It is a typical feature of many open pit mines and is now being applied to some block caves. (Henning 2018)

These technologies and methods have the potential to improve block caving projects, where there are: 
- Orebodies that have different material types, which benefit metallurgically from being separated

- Orebodies whose geometry mean that waste must be drawn before reaching ore

- Orebodies where there is a large variation in grade

In terms of its effect on the mine planning and optimisation process, in the simple case where ore sorting is after mining, and the process separates ore from waste, the technology merely changes the value of the blocks of ore and makes waste less expensive to mine.

If the technologies are used to separate low grade from high grade and process them at different times, mine planning becomes considerably more complex, with the value of the material depending on what else will be mined and hence when processing will occur.

Finally, in the situation where separation between material types is achieved underground, through campaign drawing and segregated materials handling systems the mine planning for optimisation is even more complex. In addition to the valuation of material based on its processing time, the degree of sorting that can be achieved will depend on the layout of the working areas. This can be a complex problem.

\subsection{Post cave leaching}

In post cave leaching (Newcrest Mining Limited 2018), a leaching solution is applied to broken ore in a shut-off draw-column where it dissolves the metal from the remnant broken ore. After collection, metal can be recovered from the solution without the need to further mine the ore.

Post cave leaching can add value to projects where:

- The mineralisation is leachable

- Low grade orebodies where low cost is more important than complete recovery

- Orebodies where a low grade halo above will be broken by the block caving of a high grade core below

For mine planning purposes, in situations where post cave leaching makes up a significant portion of the project revenue, the optimisation method will need to change. Best height of draw will be driven not only by the mined value of the extracted portion of the orebody but also the leach value and degree of fragmentation of the broken portion of the orebody above. Footprints may get larger to draw some uneconomic material that then results in the large scale fracturing of economic leach material above.

\section{Summary}

With reference to a range of case studies, this paper has described and demonstrated with case studies that:

- Maximising the value from a block caving project has many similarities with the planning methodology of optimising an open pit

- The use of this methodology is complicated by the greater degrees of freedom in a block cave and the more complex rules governing what is achievable

- While advances in technology will unlock value, they will further complicate the challenges of maximising that value 


\section{Conclusion}

Referring back to the question posed in the abstract, "Is value being missed?" the conclusion would be "Not necessarily". If the potential for a block cave is evaluated by designing a single footprint optimised at a breakeven cut-off, then although the mining inventory will be maximised, it is very likely that significant value will have been missed. However, if the complexity and hence the opportunity in a block caving project is properly understood and a rigorous 'open pit style' strategic planning approach is used, then value should not be missed. As described in this paper though, greater degrees of freedom and less clearly defined constraints (than in an open pit) make this a complex problem that will only become more complex with new caving technologies.

\section{References}

Henning, MG 2018, 'Grade control and segregation at New Gold's New Afton block cave operation, Kamloops, British Columbia', in Y Potvin \& J Jakubec (eds), Proceedings of the Fourth International Symposium on Block and Sublevel Caving, Australian Centre for Geomechanics, Perth, pp. 141-148.

Newcrest Mining Limited 2018, '181025_Newcrest Investor Day - Briefing Book.pdf', newcrest.com, viewed 30 July 2020 , https://www.newcrest.com/sites/default/files/2019-10/181025_Newcrest\%20Investor\%20Day\%20-\%20Briefing\%20 Book.pdf. 